\title{
Perceived Need for Medical Care in the Geriatric General Medical Population: Relationship to Neuropsychological and Psychological Function ${ }^{1}$
}

\author{
Kriscinda A. Whitney, ${ }^{2,6}$ Jennifer M. Finna, ${ }^{3}$ Julie N. Hook, ${ }^{4}$ Paul H. Lysaker, ${ }^{2}$ and Linas A. Bieliauskas ${ }^{5}$
}

\begin{abstract}
Insight is a multidimensional construct used in the psychiatric literature to refer to topics, such as awareness of symptoms of illness, awareness of consequences of illness, and perceived need for treatment. The primary aim of the present investigation was to examine both neuropsychological (i.e., executive, attention, and memory skills) and psychological contributions (i.e., depression and anxiety) to one component of insight (i.e., perceived need for medical care) among geriatric inpatients with multiple medical problems. Retrospective chart review involved analysis of data from 47 men who completed a battery of neuropsychological and psychological tests. Findings indicated that perceived need for medical care was significantly and positively related to performance on a test of executive function measuring verbal social reasoning, but not to performance on other tests of cognitive or emotional function. Theoretical and clinical implications of this result are discussed.
\end{abstract}

KEY WORDS: insight; awareness; executive function; geriatric; neuropsychological.

"Insight" is a multidimensional construct that, in the context of psychiatric research, refers to an individual's awareness of symptoms of illness, consequences of illness, and need for treatment (Amador, Straus, Yale, \& Gorman, 1991; David, 1990). It is of broad interest, given studies suggest that many individuals with severe mental illness have limited insight, which often leads to poor adherence to pharmacological and psychosocial treatment and to poor social behavioral function (Buchanan, 1992; Lysaker, Bell, Milstein, Bryson, \& Beam-Goulet, f1994; Smith et al.,

\footnotetext{
${ }^{1}$ This manuscript is an elaboration of a poster which was presented at the 32nd Annual Meeting of the International Neuropsychological Society in Baltimore, Maryland, USA, in February, 2004 (Whitney, Finna, Hook, \& Bieliauskas, 2004).

${ }^{2}$ Roudebush VA Medical Center and Indiana University School of Medicine, Indianapolis, Indiana.

${ }^{3}$ University of Michigan, Ann Arbor, Michigan.

${ }^{4}$ Rush University Medical Center, Chicago, Illinois.

${ }^{5}$ University of Michigan Health System and Department of Veterans Affairs Medical Center, Ann Arbor, Michigan.

${ }^{6}$ Correspondence should be addressed to Kriscinda Whitney, Psychiatry Ambulatory Care (116P), Roudebush VA Medical Center, 1481 W. 10th Street, Indianapolis, IN 46202; e-mail: kriscinda.whitney@med.va.gov.
}

1999; Van Putten, Crumpton, \& Coralee, 1976). Although poor insight into illness appears to be a significant factor in compliance with psychiatric treatment, we are not aware of any published studies that have examined the relationship between insight and cognitive function in a medical, not psychological, population. As having a limited awareness of illness will likely pose problems for the rehabilitation of patients with physical impairments, there is a distinct need to examine this population.

There is an emerging body of literature that supports the notion that poor insight often occurs in conjunction with neuropsychological deficits in executive function (Lysaker \& Bell, 1994; Lysaker, Bell, Bryson, \& Kaplan, 1998; Marks, Fastenau, Lysaker, \& Bond, 2000; Young, Davila, \& Scher, 1993) and with physiological frontal lobe dysfunction (e.g., Stuss, 1991). For example, results from several recent neuroimaging studies suggest that that limited insight into illness is associated with less intact frontal lobe functioning among persons with schizophrenia (Flashman, 2002) and among persons with Alzheimer's disease (Derouesne et al., 1999; Reed, Jagust, \& Coulter, 1993; Starkstein et al., 1995; for review, see Flashman, 2002). 
In addition, head injury patients with frontal lobe damage often suffer from lack of awareness of memory impairment as well as personality and behavioral changes (Bond, 1984).

One aim of the present study was to investigate the relationship between perceived need for medical care and cognitive function in a medically-ill population. It was hypothesized that perceived need for medical care would be related scores on tests of executive function associated with frontal lobe function but not to other areas of cognitive function (e.g., memory, attention, and premorbid intelligence). As research indicates that neurocognitive performance may be negatively affected by mood states (e.g., depression; Crews \& Harrison, 1995), the second aim of the study was to measure levels of depression and anxiety to examine what relationship, if any, they had to perceived need for treatment.

\section{METHOD}

The study was conducted utilizing clinical data gathered in the Extended Care Center (ECC) of the Ann Arbor Veterans Affairs Medical Center. The ECC is a 45-bed unit designed to care for veterans with a variety of medical and psychosocial problems. The ECC functions more as a rehabilitation unit rather than long-term care facility, thus there is typically a fairly rapid turnover of patients. The most common diagnoses of ECC patients include: amputations often associated with diabetes mellitus, hypertension, rheumatoid arthritis, chronic obstructive pulmonary disease, congestive heart failure, peptic ulcer disease, urinary tract infections, coronary artery disease, dermatological disorders, renal disease, mood disturbances, cerebral vascular disorders, and osteomyelitis. Upon admission to the ECC, individuals are administered a brief neuropsychological screen as part of their standard care.

Sample and Data Collection Procedures

Following IRB approval, this study was performed retrospectively using charts from 97 ECC patients. Patients' charts were eliminated if they were not administered the entire neuropsychological screen upon admission or if the patient scored lower than 23 out of 30 points on a cognitive screening measure (Mini-Mental Status Exam; Folstein, Folstein, $\&$ McHugh, 1975). The latter exclusionary criterion were used to eliminate persons whose cognitive dys-

\begin{tabular}{lcc}
\multicolumn{3}{c}{ Table I. Demographic Characteristics of the Sample $(N=47)$} \\
\hline \multicolumn{1}{c}{ Variable } & $M(S D)$ & $N(\%)$ \\
\hline Age & $65.21(10.6)$ & \\
Education & $12.77(2.7)$ & \\
Gender & \\
$\quad$ & $47(100.0 \%)$ \\
Male & \\
Ethnicity & $39(83.0 \%)$ \\
Caucasian & $7(14.9 \%)$ \\
Ofrican-American & $1(2.1 \%)$ \\
\hline
\end{tabular}

function would have likely precluded them from understanding assessment items. In total, the data from 47 patients were included. The demographic characteristics of the sample are summarized in Table I.

Measures

Peabody Picture Vocabulary test-III (PPVT-III)

The PPVT-III (Dunn \& Dunn, 1997) is a measure of receptive vocabulary, and is screening test of verbal ability as well as an indicator of premorbid intellectual functioning. During the administration of the test, the participant is read a word and is asked to select one of four pictures that most closely corresponds to the word. The vocabulary words become increasingly more difficult with each subsequent item. In total, there are 204 items, but typically the respondent only receives a portion of these items based on his/her age, education, and performance during the test. The PPVT-III test takes approximately $10-15 \mathrm{~min}$ to administer and offers an age-corrected IQ score.

\section{Mini-Mental Status Examination (MMSE)}

The MMSE (Folstein et al., 1975) is one of the most widely used brief screening instruments for cognitive dysfunction, usually taking about $5 \mathrm{~min}$ to administer. The MMSE consists of 30 items designed to assess the orientation, short-term memory, attention, language skills, and visual-spatial skills. Scores below 23 were considered impaired.

\section{The Patient's Experience of Hospitalization Questionnaire-Revised (PEH-R)}

The PEH-R is an 18-item pencil and paper measure (see Table II for a full description of the items and response format). The items address perceived need 


\begin{tabular}{|c|c|c|c|}
\hline \multicolumn{4}{|l|}{ PEH-R Items } \\
\hline \multicolumn{4}{|c|}{$\begin{array}{l}\text { 1. When someone first recommended the present treatment, how did you feel about this person's } \\
\text { recommendation for treatment? }\end{array}$} \\
\hline strongly agreed & agreed & disagreed strongly & disagreed \\
\hline \multicolumn{4}{|c|}{ 2. In general, how much do you tend to worry? } \\
\hline Not at all & slightly & moderately & a great deal \\
\hline \multicolumn{4}{|c|}{ 3. How much do you worry about your condition? } \\
\hline not at all & slightly & moderately & a great deal \\
\hline \multicolumn{4}{|c|}{ 4. How much do you worry about getting into trouble because of your condition? } \\
\hline not at all & slightly & moderately & a great deal \\
\hline \multicolumn{4}{|c|}{ 5. How much do you worry about losing friends because of your condition? } \\
\hline not at all & slightly & moderately & a great deal \\
\hline \multicolumn{4}{|c|}{ 6. How much do you worry about being unable to work because of your condition? } \\
\hline not at all & slightly & moderately & a great deal \\
\hline \multicolumn{4}{|c|}{ 7. How much do you worry about not recovering? } \\
\hline not at all & slightly & moderately & a great deal \\
\hline \multicolumn{4}{|c|}{ 8. I think my condition will go away by itself. } \\
\hline strongly agree & agree & disagree & strongly disagree \\
\hline \multicolumn{4}{|c|}{ 9. There's no doubt in my mind that I'll be better someday. } \\
\hline strongly agree & agree & disagree & strongly disagree \\
\hline \multicolumn{4}{|c|}{ 10. Do you believe the current hospital stay to be necessary? } \\
\hline definitely & probably & probably not & definitely not \\
\hline \multicolumn{4}{|c|}{ 11. If you had not gone into the hospital, how do you think you would be doing right now? } \\
\hline \multicolumn{4}{|c|}{ 12. I can gain a lot from being in the hospital. } \\
\hline strongly agree & agree & disagree & strongly disagree \\
\hline \multicolumn{4}{|c|}{ 13. I will need treatment after I leave the hospital. } \\
\hline strongly agree & agree & disagree & strongly disagree \\
\hline \multicolumn{4}{|c|}{ 14. If I were to discharged from the hospital today I would do fine. } \\
\hline strongly agree & agree & disagree & strongly disagree \\
\hline \multicolumn{4}{|c|}{ 15. How much do your thoughts and feelings interfere with getting things done? } \\
\hline not at all & slightly & moderately & a great deal \\
\hline \multicolumn{4}{|c|}{ 16. I think my condition requires medical treatment. } \\
\hline strongly agree & agree & disagree & strongly disagree \\
\hline \multicolumn{4}{|c|}{ 17. I have symptoms of physical illness. } \\
\hline strongly agree & agree & disagree & strongly disagree \\
\hline $\begin{array}{l}\text { 18. How ill do you think you are? } \\
\text { not at all ill }\end{array}$ & slightly ill & moderately ill & severely ill \\
\hline
\end{tabular}

Note. Italicized items were reverse scored.

for treatment and hospitalization, and extent of worry about illness as well as illness-related issues. The PEH$\mathrm{R}$ is a modified version of two pre-existing measures: (1) the Patient's Experience of Hospitalization (PEH: Carsky, Selzer, Terkelsen, \& Hurt, 1992) and (2) the Self-Appraisal of Illness Questionnaire (Marks et al., 2000). The PEH-R consists of four subscales of which three were employed in the present study: (1) Need for Treatment (NEEDTX), (2) Need for Hospitalization (NEEDHOSP), and (3) Worry (WORRY) (see Table III). For the NEEDTX and NEEDHOSP subscales, higher scores indicate denial of a need for treatment and hospitalization. For the WORRY subscale, higher scores indicate decreased worry. The WORRY subscale was used as a measure of anxiety in the current study. 
Table III. Relevant Subscales of the PEH-R

\begin{tabular}{lcc}
\multicolumn{1}{c}{ Subscale } & Items & Example \\
\hline NEEDTX & 13,16 & $\begin{array}{c}\text { 13-I will need treatment after } \\
\text { I leave the hospital. }\end{array}$ \\
NEEEDHOSP & $1,10-14$ & $\begin{array}{c}\text { 10-Do you believe the current } \\
\text { hospital stay to be necessary? } \\
\text { WORRY }\end{array}$ \\
& $2-7$ & $\begin{array}{c}\text { 6-How much do you worry } \\
\text { about your condition? }\end{array}$ \\
\hline
\end{tabular}

The Brief Geriatric Depression Scale (BGDS)

The BGDS (Sheik \& Yesavage,1986; Yesavage, Brink, Rose, \& Lum, 1982) is a 15 -item paper and pencil measure, which requires respondents to answer items by circling yes or no. This depression scale was designed for use with older patients, as it does not rely on somatic symptoms of depression which are often comborbid with the normal aging process (i.e., fatigue). Scores greater than five are considered to be indicative of clinically significant depression.

Frontal Assessment Battery (FAB)

The FAB (Dubois, Slachevsky, Litvan, \& Pillon, 2000) consists of six subtests, each exploring specific frontal lobe functions, and the test takes approximately $10 \mathrm{~min}$ to administer. The subtests include: (1) Similarities which requires patients to conceptualize the associations between two objects (e.g., apple and banana are both fruit), (2) Lexical Fluency which requires patients to recall as many words beginning with the letter as "s" as they can within $1 \mathrm{~min}$, (3) Motor Programming which requires patients to learn and perform a series of motor movements with their right hand, (4) Conflicting Instructions (sensitivity to interference) which requires patients to provide an alternate response to the examiner's signals (e.g., if the examiner taps twice then the patients taps once), (5) Go-No Go (inhibitory control) which requires the patient to inhibit motor responses (e.g., the patient is asked to "Tap once when I tap once" and "Do not tap when I tap twice"), and (6) Prehension Behavior (environmental autonomy), during which the patient is told, "Do not take my hands," while the examiner touches the palms of both the patient's hands, to see if the patient will spontaneously take them.

Neurobehavioral Cognitive Status Exam—Judgment Test (NCSE)

The NSCE Judgment test (Kiernan, Mueller, Langston, \& Van Dyke, 1987) is a test of verbal rea- soning that requires the test-taker to make social judgments based on hypothetical situations. During the administration of this test, patients are first given a screening question, in which if they pass, are given full credit for the test. If they do not pass the screening item, they must answer three additional social judgment questions. Based on the patient's performance, he may be categorized as having normal functioning, or impairment of a mild, moderate, or severe nature.

Measure of Attention

Wechsler Adult Intelligence Scale—Revised (WAIS-R)—Digit Span Subtest-Abbreviated Version

The WAIS-R Digit Span (Wechsler, 1981) consists a digits forward task and digits backward task. For the digits forward test, the examiner reads a list of digits at the rate of one per second, and asks the patient to repeat them. For the digits backward test, the examiner reads a list of digits at the rate of one per second, but asks the patient to repeat the numbers in a backward order. In the current study, we administered the first three trials of Digit Span forward and trials two and three of Digit Span backward. The patient's total score on the Digit Span subtest was the number of digits forward correctly repeated plus the number of digits backward correctly repeated in reverse sequence.

The Hopkins Verbal Learning Test-Revised (HVLT-R)

The Hopkins Verbal Learning Test-R (Benedict, Schretlen, Groninger, \& Brandt, 1998) assesses verbal memory. It consists of a 12 -item word list that is read to the patient three consecutive times. Each time, the patient is asked to recall the word list; then after a 20-min delay, the patient is asked to recall the words again. Finally, the patient is read a 24 -word recognition list that contains the 12 target words plus semantically related foils and 6 unrelated ones. The patient is asked to say "yes" or "no" after the presentation of each of the 24 words, depending on whether or not he/she believes the word was previously presented.

\section{RESULTS}

The mean scores for the sample on the PEH-R, neuropsychological measures, and emotional function variables, are shown in Table IV. Raw scores 
Table IV. Mean Scores for Sample on the PEH-R and Neuropsychological Measures

\begin{tabular}{|c|c|c|}
\hline Measure & $M(S D)$ & $\begin{array}{c}\text { Range of possible } \\
\text { scores/norms }\end{array}$ \\
\hline \multicolumn{3}{|l|}{$\begin{array}{l}\text { Patient's experience of } \\
\text { hospitalization-revised }\end{array}$} \\
\hline NEEDTX & $3.06(1.11)$ & $2-8$ \\
\hline NEEDHOSP & $8.49(1.67)$ & $6-24$ \\
\hline \multicolumn{3}{|l|}{ Executive functioning } \\
\hline $\begin{array}{l}\text { Frontal assessment scale } \\
\text { total score }\end{array}$ & $14.70(3.04)$ & $0-18$ \\
\hline NCSE judgment & $5.34(1.37)$ & $0-6$ \\
\hline \multicolumn{3}{|l|}{$\begin{array}{l}\text { Memory functioning } \\
\text { Hopkins verbal learning } \\
\text { test—revised }\end{array}$} \\
\hline Trials $1-3$ total & $16.94(5.21)$ & $0-36$ \\
\hline Trial 4 delay & $5.83(2.49)$ & $0-12$ \\
\hline \multicolumn{3}{|l|}{ Attentional functioning } \\
\hline $\begin{array}{l}\text { Abbreviated WAIS-III } \\
\text { digit span }\end{array}$ & $8.63(0.61)$ & $0-9$ \\
\hline \multicolumn{3}{|l|}{ Intelligence } \\
\hline $\begin{array}{l}\text { Peabody picture vocabulary } \\
\text { test-III }\end{array}$ & $98.40(10.25)$ & $\begin{array}{l}M=100 \\
S D=15\end{array}$ \\
\hline \multicolumn{3}{|l|}{ Emotional function } \\
\hline $\begin{array}{l}\text { Brief geriatric depression } \\
\text { scale }\end{array}$ & $1.85(.36)$ & $0-15$ \\
\hline PEH-R WORRY & $17.85(3.86)$ & $6-24$ \\
\hline
\end{tabular}

Note. Higher scores on the PEH-R NEEDTX and NEEDHOSP subscales indicate denial of a need for treatment and need for hospitalization, respectively. Higher scores on each of the neuropsychological measures indicate better functioning within that domain. Higher scores on the Brief Geriatric Depression scale indicate more depressive symptoms. Higher scores on the PEH-R WORRY subscale indicate less worry.

were used for all measures, with the exception of the PPVT-III, for which an estimated IQ score was used. The latter standard score has a mean of 100 and a standard deviation of 15 . One-tailed partial correlations were computed to examine the relationships among variables controlling age. PEH-R and neuropsychological functioning are shown in Table V. To control for Type I error, the alpha was set at $p<.01$ for all analyses.

As shown in Table $\mathrm{V}$, the level of awareness, as indicated by scores on the PEH-R, NEEDTX, and NEEDHOSP subscales, demonstrated a statistically significant relationship with one test of executive function (i.e., the NCSE Judgment test), but not the other, the FAB. There were no significant relationships observed between the PEH-R, NEEDTX, and NEEDHOSP subscales and tests of memory or attention. Interestingly, there were also no significant relationships observed between the NEEDTX and NEEDHOSP subscales and measures of emo-
Table V. Partial Correlations Between the PEH-R and Neuropsychological Functioning Controlling for Age

\begin{tabular}{lcc}
\hline & PEH-R & PEH-R \\
NEEDTX & NEEDHOSP \\
\hline $\begin{array}{l}\text { Executive functioning } \\
\text { Frontal assessment scale } \\
\text { total score }\end{array}$ & & \\
NCSE judgment & -.13 & .07 \\
Memory functioning & $-.42^{*}$ & $-.39^{*}$ \\
$\quad \begin{array}{l}\text { Hopkins verbal learning } \\
\text { test-revised }\end{array}$ & & \\
$\quad$ Trials 123 total & & \\
$\quad$ Trial 4 delay & -.02 & -.22 \\
Attentional functioning & .06 & -.26 \\
$\quad$ WAIS-III digit span & & \\
Intelligence & -.16 & .02 \\
Peabody picture vocabulary \\
test-III
\end{tabular}

Note. Higher scores on the PEH-R Need for Treatment subscale indicate denial of a need for treatment. Higher scores on the PEH-R Need for Hospitalization subscale indicate denial of presence of a need for hospitalization.

${ }^{*} p<.01$, one-tailed.

tional function or premorbid intelligence. Albeit, the sample did not appear to be significantly depressed, as evidenced by their lower overall BGDS scores.

\section{DISCUSSION}

Pre-existing literature suggests that impaired insight is associated with deficits in executive function in individuals with severe mental illness. However, it is unclear whether a similar relationship exists among persons with medical illness. The primary aim of the present investigation was to examine both neuropsychological (i.e., executive, attention, and memory skills) and psychological contributions (i.e., depression and anxiety) to perceived need for medical care among geriatric inpatients with multiple medical problems.

Results of this investigation suggested that perceived need for medical care among persons with medical illness was positively related to the ability to make abstract social judgments. No relationships were found between perceived need for medical care and performance on the FAB or tests of premorbid intelligence, memory, attention, depression, or anxiety. Taken together, these results suggest that 
impairments in social reasoning may uniquely limit person's ability to appraise their need for treatment when faced with medical illnesses. The failure to find associations between insight and the FAB, also a test of executive function, may suggest that deficits in motoric and nonsocial reasoning capacities tapped by the FAB are not sufficient in and of themselves to limit awareness of need for treatment.

Within the psychiatric literature, research supports the assumption that lack of awareness of illness is associated with poor treatment compliance (Buchanan, 1992; Lysaker et al., 1994). As noted, the NCSE Judgment subtest is frequently employed to assist in determining competency and judgment in medical patients. Given its relationship with PEH-R, NEEDTX, and NEEDHOSP, further attention should be given to these two subscales as they too may serve as a brief screening instrument for patients who may be at risk for nontreatment compliance due to poor comprehension of their illnesses and denial of a need for medical care. In addition, these scales may serve as a guide for intervention, in which the beginning stages of treatment may be to assist the patient in understanding the importance of medical care.

Certainly, there are limitations to the study (e.g., an all male veteran sample) and replication of results is needed before more definitive conclusions can be drawn. Nevertheless, the need to attend to fundamental judgment abilities in primarily psychologically healthy individuals is supported. Further studies should investigate whether changes in underlying frontal cortical systems are involved in patient compliance with medical care.

\section{REFERENCES}

Amador, X. F., Straus, D. H., Yale, S. A., \& Gorman, J. M. (1991). Awareness of illness in schizophrenia. Schizophrenia Bulletin, $17,113-132$.

Benedict, R. H. B., Schretlen, D., Groninger, L., \& Brandt, J. (1998). Hopkins Verbal Learning Test-Revised: Normative data and analysis of inter-form and test-retest reliability. The Clinical Neuropsychologist, 12(1), 43-55.

Buchanan, A. (1992). A two-year prospective study of treatment compliancein patients with schizophrenia. Psychological Medicine, 22(3), 787-797.

Carsky, M., Selzer, M. A., Terkelsen, K., \& Hurt, S. W. (1992). The PEH: A questionnaire to assess acknowledgement of Psychiatric Illness. The Journal of Nervous and Mental Disease, 180(7), 458-464.

Crews, W.D., Jr., \& Harrison, D.W. (1995). The neuropsychology of depression and its implications for cognitive therapy. Neuropsychology Review, 5, 81-123.
David, A. S. (1990). Insight and psychosis. British Journal of Psychiatry, 156, 798-805.

Derouesne, C., Thibault, S., Lagha-Pierucci, S., Baudouin-Madec, V., Ancri, D., \& Lacomblez, L. (1999). Decreased awareness of cognitive deficits in patients with mild dementia of the Alzheimer type. International Journal of Geriatric Psychiatry, 14(12), 1019-1030.

Dubois, B., Slachevsky, A., Litvan, I., \& Pillon, B. (2000). A frontal assessment battery at bedside. Neurology, 55, 1621-1626.

Dunn, L. M., \& Dunn, L. M. (1997). Peabody Picture Vocabulary test (PPVT-III) (3rd ed.). Circle Pines, MN: AGS Publishing.

Flashman, L. A. (2002). Disorders of awareness in neuropsychiatric dyndromes: An update. Current Psychiatry Reports, 4, 346353.

Folstein, M. F., Folstein, S. E., \& McHugh, P. R. (1975). "Minimental state": A practical method for grading the cognitive state of patients for the clinician. Journal of Psychiatric Research, 12(3), 189-198.

Kiernan, R. J., Mueller, J., Langston, J. W., \& Van Dyke, C. (1987). The Neurobehavioral Cognitive Status Examination: a brief but quantitative approach to cognitive assessment. Annals of Internal Medicine, 107(4), 481-485.

Lysaker, P., \& Bell, M. (1994). Insight and cognitive impairment in schizophrenia: Performance on repeated administrations of the Wisconsin Card Sorting Test. The Journal of Nervous and Mental Disease, 182, 656-660.

Lysaker, P. H., Bell, M. D., Bryson, G., \& Kaplan, E. (1998). Neurocognitive function and insight in schizophrenia: support for an association with impairments in executive function but not with impairments in global function. Acta Psychiatrica Scandinavica, 97(4), 297-301.

Lysaker, P., Bell, M., Milstein, R., Bryson, G., \& Beam-Goulet, J. (1994). Insight and psychosocial treatment compliance in schizophrenia. Psychiatry, 57, 307-315.

Marks, K. A., Fastenau, P. S., Lysaker, P. H., \& Bond, G. R. (2000). Self-Appraisal of Illness Questionnaire (SAIQ): Relationship to researcher-rated insight and neuropsychological function in schizophrenia. Schizophrenia Research, 45, 203-211.

Smith, T. E., Hull, J. W., Goodman, M., Hedayat-Harris, A., Wilson, D. F., Israel, L. M., et al. (1999). The relative influences of symptoms, insight, and neurocognition on social adjustment in schizophrenia and schizoaffective disorder. The Journal of Nervous and Mental Disease, 187(2), 102-108.

Sheikh, J. I., \& Yesavage, J. A. (1986). Geriatric Depression Scale (GDS): Recent evidence and development of a shorter version. In T. L. Brink (Ed.), Clinical gerontology: A guide to assessment and intervention (pp. 165-173). New York: The Haworth Press.

Starkstein, S. E., Vazquez, S., Migliorelli, R., Teson, A., Sabe, L., \& Leiguarda, R. (1995). A single-photon emission computed tomographic study of anosognosia in Alzheimer's disease. Archives of Neurology, 52(4), 415-420.

Stuss, D. T. (1991). Disturbance of self-awareness after frontal lobe damage. In G. P. Prigatano \& D. L. Schacter (Eds.), Awareness of deficit after brain injury (pp. 63-83). New York, NY: Oxford University Press.

Van Putten, T., Crumpton, E., \& Coralee, Y. (1976). Drug refusal in schizophrenia and the wish to be crazy. Archives of General Psychiatry, 33, 1443-1447.

Yesavage, J. A., Brink, T. L., Rose, T. L., \& Lum, O. (1982). Development and validation of a geriatric depression screening scale: A preliminary report. Journal of Psychiatry, 17, 3749.

Young, D. A., Davila, R., \& Scher, H. (1993). Unawareness of illness and neuropsychological performance in chronic schizophrenia. Schizophrenia Research, 10, 117-124. 